\title{
SYNTHESIS AND BIOLOGICAL ACTIVITY OF FOUR ANALOGUES OF $\beta$-CORTICOTROPIN*
}

\author{
BY
}

\author{
G. I. TESSER and J. T. BUIS
}

(Department of Organic Chemistry, R. C. University, Nijmegen, The Netherlands)

The syntheses of four ACTH-analogues: [Orn $\left.{ }^{15-18}\right]$, [D-Ser $\left.{ }^{1}, \operatorname{Orn}^{15-18}\right]$-, [Orn $\left.{ }^{11,13-18}\right]$ - and [D-Ser ${ }^{1}$. Orn $\left.{ }^{11,15-18}\right]-\beta$-corticotropin-(1-18)-octadecapeptide amide** are described. The last mentioned compound exhibits an unexpected, strongly prolonged, biological activity. A possible explanation is given.

In previous investigations it has been shown that the arginine residues in positions 17 and 18 of the natural sequence of ACTH can be substituted by ornithine without loss in potency. [Orn $\left.{ }^{17,18}\right]-\beta$-corticotropin(1-24)-tetracosapeptide is as potent in vitro and in vivo as the unmodified tetracosapeptide ${ }^{1}$. Since the diornithine analogue is more readily synthesized than the original diarginine polypeptide, a similar substitution was carried out with respect to the remaining arginine residue in position 8. However, in vivo adreno-corticotropic activity of [Orn $\left.{ }^{8}\right]$ - as well as [Orn $\left.{ }^{8,17,18}\right]-\beta$-corticotropin-(1-24)-tetracosapeptide-appeared to be reduced to about $1 \%$ of that of the "natural" tetracosapeptide 2 .

As the nature of the basic amino acids 17 and 18 in the natural sequence Lys-Lys-Arg-Arg (positions 15 to 18), which has long been regarded as a binding site ${ }^{3}$, appears not critical (a [Lys $\left.{ }^{17,18}\right]$-analogue also has proved to be fully active ${ }^{4}$ ), it seemed appropriate to investigate the influence of further substitutions in which the lysine residues 15 and 16 , and even 11 are also replaced by ornithine.

An inducement for investigating such substitutions is that the susceptibility of basic amino acid derivatives towards tryptic hydrolysis depends strongly on the length of the side chain bearing the positive charge;

* Nomenclature of P. H. Bell. J. Am. Chem. Soc. 76, 5565 (1954). According to C. H. Li. Science 129, 969 (1959) the compound should be named $\alpha$-adrenocorticotropin.

* Designation and abbreviation according to the IUPAC-IUB Commission on Biological Nomenclature. Biochemistry 6, 362 (1967).

1 G. I. Tesser and R. Schwyzer, Helv. Chim. Acta 49. 1013 (1966).

${ }^{2}$ G. I. Tesser and W. Rittel, Rec. Trav. Chim. 88, 553 (1969).

${ }^{3}$ K. Hofmann, Brookhaven Symp. Biol. 13, 184 (1960).

${ }^{4}$ B. Riniker and W. Rittel, Helv. Chim. Acta 53, 513 (1970). 
hydrolysis of ornithyl derivatives by trypsin is very slow in comparison with corresponding arginyl or lysyl derivatives ${ }^{5-7}$.

With a simple $\mathrm{p}_{\mathrm{H}}$-stat technique ${ }^{8}$ we found that phthaloyl-glycyl-Lornithine methyl ester hydrochloride (II), in the concentration range where zero order kinetics are followed, hydrolyzes about 20 times slower than its lysine analogue, I, under the influence of trypsin (Fig. 1).

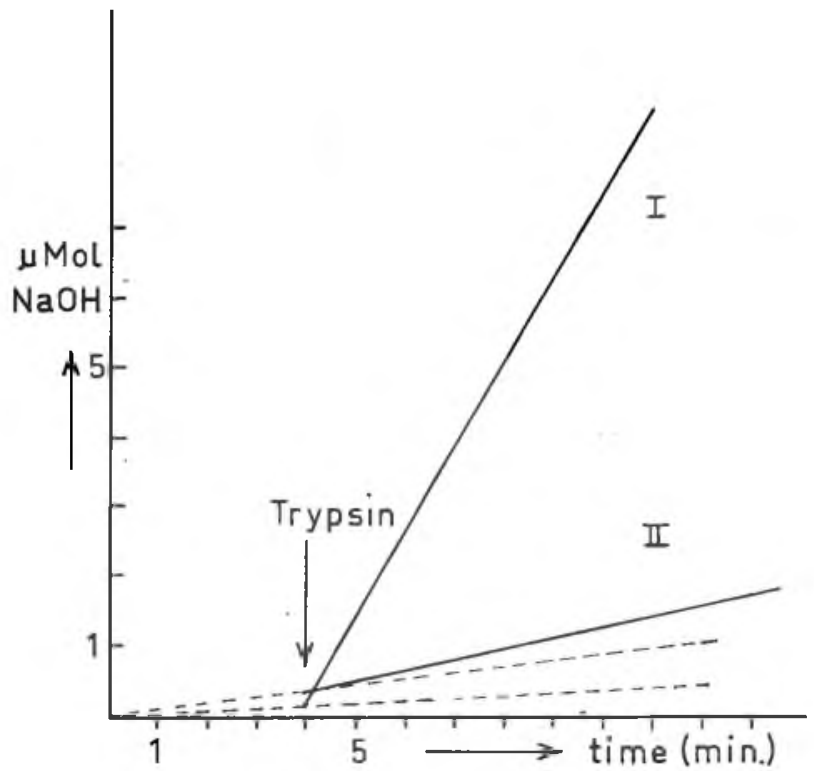

Fig. 1. Velocity of trypsin-catalyzed hydrolysis of an ornithine ester (II) relative to its lysine analogue (I). Dotted lines represent production of acid, due to spontaneous hydrolysis (for I and II) and lactam formation (for II).

If, therefore, substitution of lysine residues in corticotrophic peptides by ornithine should not substantially reduce biological potency, an expected increase in stability might eventually lead to prolonged activity. For that reason, in the evaluation of corticotrophic properties of the new analogues investigated, special attention was paid to the duration of steroidogenesis, using a method described by Dessaulles and Rittel ${ }^{9}$.

5 E. Brand, A. A. Plentl and B. F. Erlanger, Abstr. Pap. Am. Chem. Soc., 116 th Meeting, Atlantic City, p. 27C (1949).

6 N. Izumiya, T. Okazaki, I. Matsumoto and H. Takiguchi, J. Biochem. 46, 1377 (1959).

7 N.J. Baines, J. B. Baird and D. T. Elmore, Biochem. J. 90, 470 (1964).

${ }^{8}$ G. I. Tesser, R.J. F. Nivard and M. Gruber, Bioch. Bioph. Acta 89, 303 (1964).

9 P. A. Dessaulles and W. Rittel, Mem. Soc. Endocrin. 17, 125 (1968),; Eds. V. H. F. James and $J$. Landon, Cambridge. 
Because the shortest fragment of ACTH which displays full biological activity is the octadecapeptide having the amino terminal sequence $(1-18)^{10,11}$, analogues of this peptide have been synthesized and tested. Generally, the activity of short, amino terminal ACTH fragments is enhanced by terminating the chain with an amide group ${ }^{11}$. This has also been done in this investigation (Fig. 2).

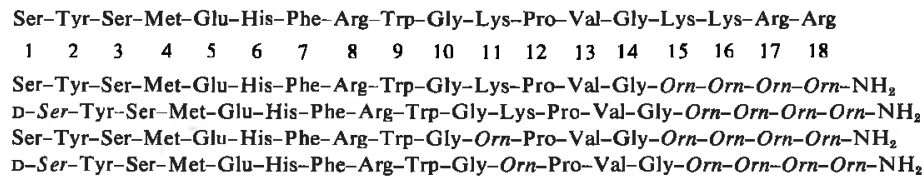

Fig. 2. Natural sequence 1-18 of corticotropin (A) and analogues investigated (B-E).

It has been shown ${ }^{9}$ that substitution of the unnatural $\mathrm{D}$-serine for L-serine in position 1 doubles the duration of steroidogenesis following subcutaneous injection (into rats) of a tetracosapeptide containing the natural sequence.

A similar substitution in [Orn $\left.{ }^{17,18}\right]-\beta$-corticotropin-(1-24)-tetracosapeptide causes an even more pronounced prolongation of activity ${ }^{9}$. Therefore, compounds $\mathrm{C}$ and $\mathrm{E}$ (fig. 2) have also been prepared and tested.

\section{Synthetic design}

The syntheses of two fully protected octapeptide amides, representing the carboxyl terminal parts of compounds B (and C) and D (and E) respectively, is shown in scheme $I$. They were obtained from the protected tetrapeptides (XIIa and b) bearing a lysyl or an ornithyl group as $N$-terminal amino acid and the partially protected tetrapeptide ester IX, by condensation with dicyclohexylcarbodiimide.

The fully protected tetrapeptide ester VIII was obtained from the ornithyl ornithine derivatives VI and VII by the method of Weygand and $W$ ünsch ${ }^{12}$, in which racemization is completely suppressed by virtue of a low reaction temperature and the addition of $N$-hydroxysuccinimide.

The final conversion of the esters XIIIa and XIIIb into amides was effected with methanolic ammonia. The reactions were slow, and the end-products, although crystalline, had to be purified by counter-current distribution.

${ }^{10}$ R. Schwyzer, Ann. Rev. Biochem. 33, 259 (1964).

11 J. Ramachandran, D. Chung and C. H. Li, J. Am. Chem. Soc. 87, 2696 (1965).

${ }^{12}$ F. Weygand, D. Hoffmann and E. Wünsch, Z. Naturforsch. 21b, 426 (1966). 


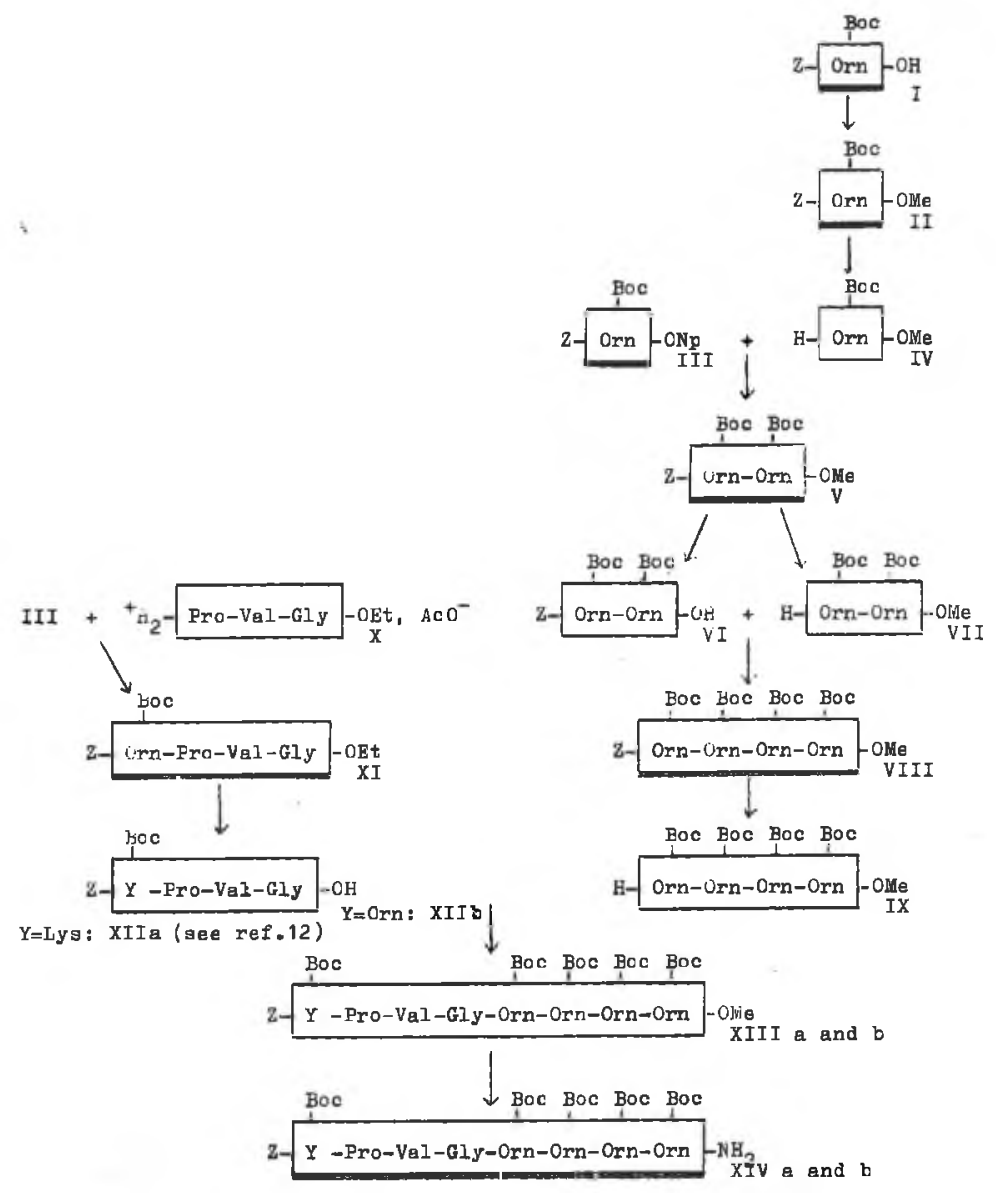

Scheme I

For the preparation of compounds (B-E) (scheme II) the amides $\mathrm{XIVa}$ and $\mathrm{XIVb}$ were hydrogenolyzed in a slightly acidic medium. The resulting hydrochlorides $\mathrm{XVa}$ and $\mathrm{XVb}$ were coupled with the appropriate protected decapeptides XVIa and $\mathrm{XVIb}^{13}$, using dicyclohexylcarbodiimide as the condensing agent without an additional equivalent of base.

After counter-current distribution the protected octadecapeptides XVIIa-d were obtained in the acetate form in yields of $50-70 \%$.

1s R. Schwyrer and W. Rittel, Helv. Chim. Acta 44, 159 (1961). 


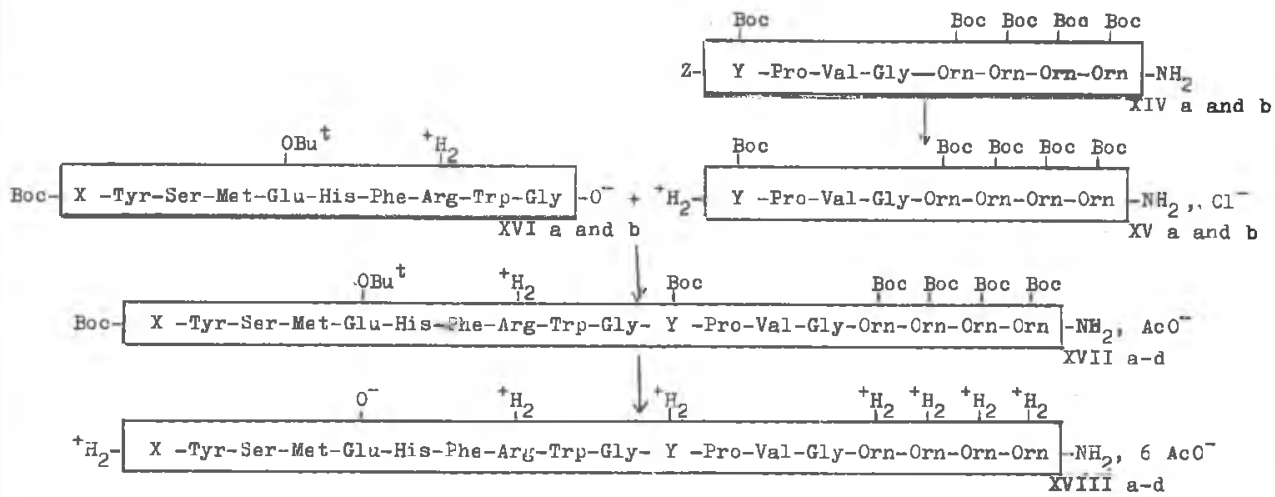

Scheme II

Removal of protecting groups with $90 \%$ trifluoroacetic acid, and exchange of trifluoroacetate by acetate ions through filtration through a short column of weakly basic ion exchanger in the acetate form was performed with quantitative yield.

\section{Biological Activity*}

Results of activity measurements, represented in Table I and Fig. 3, reveal that all compounds (B-E) show corticotrophic activity. With compounds B and D, in which 4 or 5 basic amino acids (lysine and arginine) have been replaced by ornithine the adrenal steroid excretion, half an hour after subcutaneous injection, is comparable with that of an equal dose of the reference compound (A). However, duration of steroidogenesis is substantially decreased.

Inversion of the configuration of the $N$-terminal serine residue prolongs the duration of activity of both compounds B and D about fourfold. In comparison with the standard $A$, compound $E$ in particular produces a strongly protracted steroidogenesis.

Our results confirm that inversion of configuration of the serine residue

* Biological activities were determined at the Biological Research Laboratories, Pharmaceutical Division, Ciba Ltd., Basel, Switzerland. We are greatly indebted to Dr. P. A. Dessaulles and Dr. R. Maier for performing the tests. 
Table I

Plasma corticosterone concentration $(\mu \mathrm{g} / 100 \mathrm{ml})$ following subcutaneous application of ACTH analogues $(0.3$ $\mathrm{mg} / \mathrm{kg}$ body weight) in rats that were hypophysectomized $24 \mathrm{~h}$ previously (compare ref. 9 ).

\begin{tabular}{|c|c|c|c|c|c|c|c|c|c|}
\hline & Compound & $\begin{array}{c}\text { Number } \\
\text { of } \\
\text { animals }\end{array}$ & $\frac{1}{2} h$ & $1 \mathrm{~h}$ & $1 \frac{1}{2} h$ & $2 \mathrm{~h}$ & $4 \mathrm{~h}$ & $6 \mathrm{~h}$ & $8 \mathrm{~h}$ \\
\hline E & 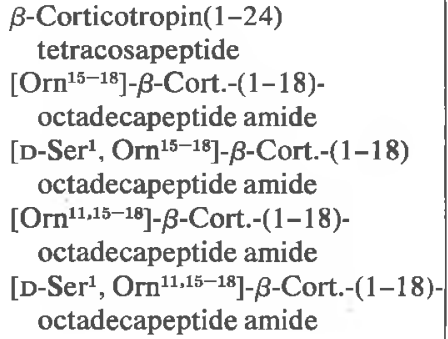 & 18 & $\begin{array}{l}30.3 \pm 2.5 \\
29.5 \pm 2.1 \\
17.2 \pm 2.0 \\
25.0 \pm 2.7 \\
29.7 \pm 6.8\end{array}$ & $\begin{array}{l}30.2 \pm 2.5 \\
<1 \\
20.4 \pm 1.7 \\
7.2 \pm 0.6 \\
29.9 \pm 2.8\end{array}$ & $\begin{array}{l}14.3 \pm 2.9 \\
<1 \\
20.4 \pm 5.3 \\
<1 \\
28.1 \pm 0.9\end{array}$ & $\begin{array}{l}1.7 \pm 1.7 \\
<1 \\
16.8 \pm 6.2 \\
<1 \\
25.4 \pm 2.2\end{array}$ & $\begin{array}{l}<1 \\
<1 \\
<1 \\
<1 \\
15.0 \pm 2.4\end{array}$ & $\begin{array}{l}<1 \\
<1 \\
<1 \\
<1 \\
<1\end{array}$ & $\begin{array}{l}<1 \\
<1 \\
<1 \\
<1 \\
<1\end{array}$ \\
\hline
\end{tabular}




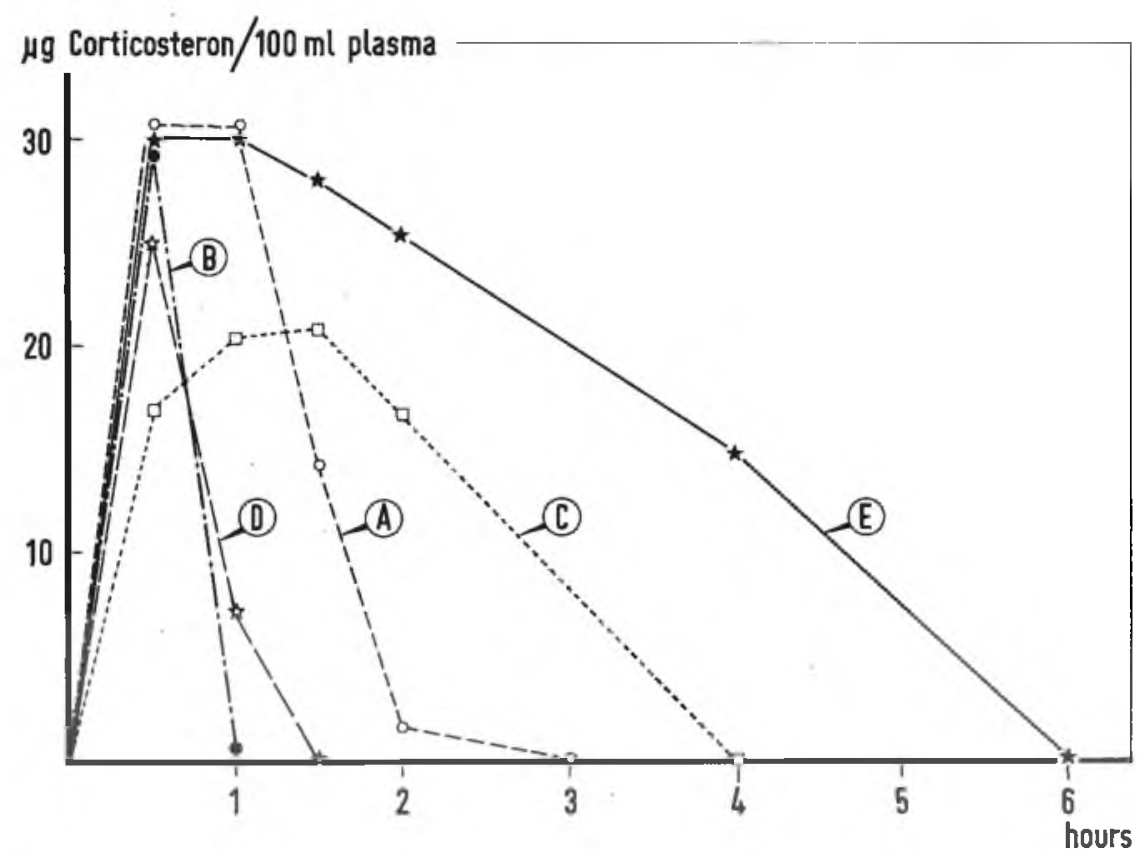

Fig. 3. Adrenocortical response to the subcutaneous injection of one single dose of the analogues $\mathrm{B}-\mathrm{E}$ in hypophysectomized rats, compared with the effect elicited by the same dose of the aminoterminal tetracosapeptide of $\beta$-corticotropin (A).

in position 1 in ACTH analogues always leads to prolonged activity, which may be caused by hampered hydrolysis by aminopeptidases.

Substitution of ornithine for lysine in position 11 (D versus $\mathrm{B}$, and $\mathrm{E}$ versus $\mathrm{C}$ ) seems to have a similar, but smaller effect. It needs further studies to determine whether or not the lysyl-prolyl bond (positions 1112 ) is a second point of attack in the enzymic degradation of corticotropins in vivo.

Substitution of lysine and arginine residues in the strongly basic part (15-18) by ornithine does not abolish biological activity. However, simultaneous exchange of all of them leads to analogues with reduced and especially shortened activity.

\section{Experimental part}

Melting points were determined with a Heiztisch Microscope (Leitz) and are uncorrected. Specific rotations were measured with a Zeiss-Winkel Polarimeter. Counter-current distributions were carried out with an instrument from Labortec (Basel).

In thin layer chromatography on silica (TS), Kieselgel G (Merck) was used predominantly with benzene-acetone (Be-An) or chloroform-methanol mixtures in the proportions 
specified for each case as solvent systems. In TLC on alumina covered plates (TA) the systems 52: $n$-butanol-acetic acid-water (100:10:30), 52A: $n$-butanol-acetic acid-water (100:15:34) or 101B: $n$-butanol-pyridine-acetic acid-water $(40: 24: 6: 30)$ were used.

\section{Scheme 1 .}

Z-Orn(Boc)-OMe (II)

$9.15 \mathrm{~g} \mathrm{(25}$ mmoles) of Z-Orn(Boc)-OH (I) ${ }^{1}$ were added to an ethereal solution of diazomethane containing a small excess of the reagent. After the evolution of nitrogen had ceased the reaction mixture was kept at room temperature for two hours and residual diazomethane was destroyed by dropwise addition of glacial acetic acid. The solution was then evaporated to dryness leaving the methyl ester in theoretical yield. The white solid was purified by crystallization from ether-petroleum ether $(1: 2)$ or from diisopropyl ether. M.p. $71^{\circ} ;[\alpha]_{\mathrm{D}}{ }^{27^{\circ}}=-14.4^{\circ}(c=1.08$ in $90 \% \mathrm{AcOH})$; TS: $R_{f}=0.69 . \mathrm{Be}_{\mathrm{C}} \mathrm{An}(1: 1) ; 0.83$, $\mathrm{CHCl}_{3}-\mathrm{MeOH}(4: 1)$.

\section{Analysis: $\mathrm{C}_{19} \mathrm{H}_{28} \mathrm{~N}_{2} \mathrm{O}_{6} \quad$ Calcd. C59.98 H 7.42 N 7.36}

$\begin{array}{llll}(380.43) & \text { Found } \mathrm{C} 60.0 & \text { H } 7.3 & \mathrm{~N} 7.3\end{array}$

\section{Pht-Gly-Orn(Boc)-OMe}

$3.8 \mathrm{~g}$ (10 mmoles) of the foregoing ester II were dissolved in $20 \mathrm{ml} 90 \%$ acetic acid and hydrogenated in the presence of $50 \mathrm{mg}$ of palladium on charcoal $(10 \%)$. After some minutes the uptake of hydrogen ceased when $245 \mathrm{ml}$ had been absorbed. The suspension was filtered and the filtrate evaporated to dryness. The residue was dried briefly at a pressure of $10^{-2} \mathrm{~mm}$ and a bath temperature of $40^{\circ}$, then taken up in chloroform (15 ml) containing one equivalent of triethylamine $(1.4 \mathrm{ml} ; 10$ mmoles), subsequently cooled in an ice bath and brought into reaction with phthaloylglycyl chloride by dissolution of $2.24 \mathrm{~g}$ (10 mmoles) of the latter in the reaction mixture.

An exothermic reaction set in. The next day the solution was washed with water, saturated sodium bicarbonate solution, citric acid solution (1\%) and again with water. After drying and evaporation of the solvent a crystalline mass remained which was recrystallized from ethyl acetate. Yield $3.42(79 \%)$. m.p. $173^{\circ}$ (very sharp), $[\alpha]_{D}{ }^{22^{\circ}}=-7.5 \pm 1^{\circ}(c=0.974$ in $\mathrm{MeOH})$; TS: $\boldsymbol{R}_{f}=\mathbf{0 . 6 1}$, Be-An $(1: 1) ;=0.84, \mathrm{CHCl}_{3}-\mathrm{MeOH}(4: 1) ;=0.71$, system 52 .

Analysis: $\mathrm{C}_{21} \mathrm{H}_{27} \mathrm{~N}_{3} \mathrm{O}_{7}$ Calcd. C 58.19 H 6.28 N 9.70

$\begin{array}{llll}\text { (433.45) Found C } 58.2 \quad \text { H } 6.3 & \text { N } 9.9\end{array}$

\section{Pht-Gly-Orn-OMe. $\mathrm{HCl}$}

Selective elimination of the side chain protection in the foregoing dipeptide ester was effected by dissolution of $1.3 \mathrm{~g}$ ( 3 mmoles) of the compound in $15 \mathrm{ml}$ of $1 \mathrm{~N}$-methanolic hydrogen chloride. After two hours at room temperature volatile components of the solution were evaporated in vacuo and the resulting solid ester hydrochloride was recrystallized from methanol-ether. Yield $1.11 \mathrm{~g}(100 \%)$, colourless needles, melting-after a phase transformation near $200^{\circ}-$ at $225-230^{\circ}$ (decomp.); at this temperature crystals suddenly reappeared, and on further heating they melted sharply at $262^{\circ} .[\alpha]_{\mathrm{D}}{ }^{22}=-16.0 \pm 1^{\circ}(c=$ 1.020 in methanol). TS: $R_{f}=0.13$ (tailing), $\mathrm{CHCl}_{3}-\mathrm{MeOH}(4: 1) ;=0.0, \mathrm{Be}-\mathrm{An}(1: 1) ;=$ 0.29 , system 52 . 


\section{Z-Orn(Boc)-Orn(Boc)-OMe (V)}

$5.0 \mathrm{~g}$ (13.2 mmoles) of Z-Orn(Boc)-OMe (II) were hydrogenolyzed in methanol $(50 \mathrm{ml})$ containing an equivalent amount of glacial acetic acid and palladium on charcoal (10\%). After filtration and evaporation of the solvent, the residue was dissolved in $10 \mathrm{ml}$ of dimethylformamide and $6.57 \mathrm{~g}$ (13.9 mmoles) of Z-Orn(Boc)-ONp (III) ${ }^{1}$ were added. A slightly exothermic reaction set in and after 16 hours at room temperature the dipeptide ester was isolated by dilution with $250 \mathrm{ml}$ of water, which caused crystallization: $10.3 \mathrm{~g}$ of crude product were obtained.

This material was purified by crystallization from a mixture of $30 \mathrm{ml}$ of boiling methanol and $25 \mathrm{ml}$ of water at the same temperature. On cooling slowly to room temperature and further down to $0^{\circ}, 7.4 \mathrm{~g}$ of the product were obtained. This purification was repeated once more to remove the last traces of $p$-nitrophenol. Yield $7.2 \mathrm{~g}(93 \%) ;$ M.p. $125^{\circ},[\alpha]_{\mathrm{D}}{ }^{20}=$ $-15.1 \pm 1^{\circ}(c=1.34$ in $90 \% \mathrm{AcOH})$. TS: $R_{f}=0.71$. Be-An $(1: 1) ;=0.85$, chloroformmethanol $(4: 1)$.

Analysis: $\mathrm{C}_{29} \mathrm{H}_{46} \mathrm{~N}_{4} \mathrm{O}_{9}$ Calcd. C 58.85 H 7.72 N 9.63

(594.69) Found C 58.7 H $7.8 \quad$ N 9.4

\section{Z-Orn(Boc)-Orn(Boc)-Orn(Boc)-Orn(Boc)-OMe (VIII)}

(a) Z-Orn(Boc)-Orn(Boc)-OH (VI). $-8.1 \mathrm{~g}$ (13.65 mmoles) of the protected dipeptide ester (V) were dissolved in $68.2 \mathrm{ml}$ of pure dioxane and $68.2 \mathrm{ml}$ of $0.2 \mathrm{~N}$-aqueous sodium hydroxide were added dropwise with stirring. The mixture was concentrated to about one quarter of its volume and a slightly yellow, but perfectly clear solution was obtained. On addition of $15.1 \mathrm{~g}$ (13.65 mmoles) of citric acid a white precipitate formed, which dissolved easily in added ethyl acetate. The lower layer was replaced by fresh citric acid solution (1\%). The organic phase, after extraction, was washed with water until neutral, dried and evaporated to leave a thick oil, that changed into a crisp foam on drying in a high vacuum. Yield, $8.5 \mathrm{~g}(100 \%)$, chromatographically homogeneous. TS: $R_{f}=0.03, \mathrm{Be}-\mathrm{An}(1: 1) ;=0.22$, chloroform-methanol $(4: 1) \cdot[\alpha]_{\mathrm{D}}{ }^{20}=-3.1 \pm 1^{\circ}(c=1$, in methanol).

(b) $\mathrm{H}$-Orn(Boc)-Orn(Boc)-OMe (VII). $-6.4 \mathrm{~g}(10.8 \mathrm{mmoles})$ of the same ester V, but free from $p$-nitrophenol, were hydrogenolyzed in pure methanol $(64 \mathrm{ml})$ in the presence of $600 \mathrm{mg}$ of palladium on charcoal (10\%). Within $5 \mathrm{~min}$. the uptake of hydrogen came to an end and slightly more than the theoretical quantity had been absorbed. The solution was filtered and to the filtrate - which was free from any starting material as could be demonstrated by thin layer chromatography $-6.3 \mathrm{~g}$ (10.8 mmoles) of the carboxyl component (VI) were added directly to prevent the formation of cyclization products.

(c) Z-Orn(Boc)-Orn(Boc)-Orn(Boc)-Orn(Boc)-OMe (VIII). The methanolic solution as obtained under (b) was evaporated to dryness and the residue was dissolved in dimethylformamide $(25 \mathrm{ml})$. A small amount of methanol still present in the solution was removed in vacuo. In order to prevent racemisation in the coupling step, two equivalents (2.48 g, 21.6 mmoles) of $N$-hydroxysuccinimide were added ${ }^{13}$ to the solution and the mixture was cooled to $-20^{\circ}$. Keeping the contents of the reaction flask at this temperature, $2.45 \mathrm{~g}$ (21.6 mmoles) of dicyclohexylcarbodiimide were added to effect coupling. The homogeneous solution was put in a refrigerator at $-20^{\circ}$ for 6 hours and then at $0^{\circ}$ for a period of 18 hours.

After filtration to remove dicyclohexylurea, evaporation of the solvent at $0.01 \mathrm{~mm}$, dissolution of the residue in ethyl acetate and filtration to remove a small amount of insoluble material, the solution was extracted with water $(3 \times 50 \mathrm{ml})$, saturated sodium bicarbonate solution $(3 \times 50 \mathrm{ml}), 1 \%$ citric acid solution $(3 \times 60 \mathrm{ml})$ and finally with water until neutral reaction of the aqueous layer. The resulting solution was dried and evaporated in vacuo. 
The product weighed $\sim 11 \mathrm{~g}$. Further purification was effected by dissolution in methanol $(100 \mathrm{ml})$ at $60^{\circ}$, followed by addition of water at the same temperature to insipient cloudiness. The slightly turbid mixture was allowed to cool down to room temperature and the protected tetrapeptide ester precipitated in the form of fine white microcrystals. Yield $8.21 \mathrm{~g}(74 \%)$.

No useful material could be isolated from the mother liquor. M.p. $152^{\circ}$, chromatographically homogeneous. TS: $\boldsymbol{R}_{f}=0.36, \operatorname{Be}-$ An $(1: 1) ;=0.91$, chloroform-methanol $(4: 1) \cdot[\alpha]_{\mathrm{D}}^{20}=-17.8 \pm 1^{\circ}(c=1$ in methanol $)$.

$\begin{array}{llll}\text { Analysis: } & \mathrm{C}_{48} \mathrm{H}_{82} \mathrm{~N}_{8} \mathrm{O}_{5} & \text { Calcd. 57.52 } & \text { H } 8.08 \mathrm{~N} 10.95 \\ 1023.24 & \text { Found C 57.5 } & \text { H 8.0 } & \text { N } 10.9\end{array}$

\section{Z-Orn (Boc)-Pro-Val-Gly-OEt (XIb)}

$6.5 \mathrm{~g}$ (15 mmoles) of Z-Pro-Val-Gly-OEt were hydrogenolyzed in methanol $(130 \mathrm{ml})$ containing $4.5 \mathrm{ml}$ of acetic acid. The tripeptide ester was isolated as acetate and used as such in the next step.

The salt $\mathrm{X}$, dissolved in $40 \mathrm{ml}$ of dimethylformamide, was brought into reaction with $8.78 \mathrm{~g}$ (18 mmoles) of Z-Orn(Boc)-ONp (III) for 16 hours at room temperature. The product was isolated by filtration from some insoluble material, dilution of the filtrate with water (four times its original volume), extraction of the turbid mixture with ethyl acetate, removal of $p$-nitrophenol from the extract by washing with sodium carbonate solution (5\%) until the water layer was virtually free from this by-product, extraction with citric acid solution, then with water until neutral and finally with brine, drying with magnesium sulfate, concentration to about $40 \mathrm{ml}$ and dilution with diisopropyl ether to $250 \mathrm{ml}$.

The product separated; it was filtered and washed with the same solvent. Further purification was achieved by crystallization from ethanol/diisopropyl ether. Yield: $8.18 \mathrm{~g}(84 \%)$.

M.p. $125^{\circ}$. TS: $R_{f}=0.41$, Be-An $(1: 1) ;=0.84$, chloroform-methanol $(4: 1)$. $[\alpha]_{\mathbb{D}}{ }^{23}=$ $-79.4 \pm 1.0^{\circ}(c=1$ in methanol).

Analysis: $\mathrm{C}_{31} \mathrm{H}_{47} \mathrm{~N}_{5} \mathrm{O}_{9} \quad$ Calcd. C $59.33 \mathrm{H} 7.62 \mathrm{~N} 10.81$

(647.75) Found C 59.5 H 7.7 N 10.9

\section{Z-Orn(Boc)-Pro-Val-Gly-OH, (XIIb; Y=Orn)}

$3.14 \mathrm{~g}$ ( 5 mmoles) of the foregoing protected tetrapeptide ester were dissolved in $80 \mathrm{ml}$ of pure dioxane and hydrolyzed by addition of an equivalent amount of sodium hydroxide in the same volume of water ( $80 \mathrm{ml}$ of $0.0625 \mathrm{~N}-\mathrm{NaOH} ; 5$ mmoles $)$. The clear yellow solution was then concentrated to about half of its volume until a turbidity appeared. On addition of $\sim 10$ mmoles of citric acid an oil separated but the solution remained yellow. Extraction of the emulsion with ethyl acetate $(2 \times 100 \mathrm{ml})$, of the combined extracts with citric acid solution and finally with water $(3 \times 100 \mathrm{ml})$ gave, after drying and evaporation of the solvent, a residue, that on addition of diisopropyl ether changed into an easily filterable powder; $3.1 \mathrm{~g}(100 \%)$. The acid isolated in this way melted unsharply at $95^{\circ}$. TS: $R_{f}=$ 0.0 , Be-An $(1: 1) ;=0.13$, chloroform-methanol $(4: 1) .[\alpha]_{\mathrm{D}}{ }^{22}=-66.5 \pm 1^{\circ}(c=1$ in methanol).

\section{Z-Y(Boc)-Pro-Val-Gly-Orn(Boc)-Orn(Boc)-Orn(Boc)-Orn(Boc)-OMe, (XIIIa and b)}

$X I I I a, Y=$ Lys. Neutral hydrogenolysis of $4.1 \mathrm{~g}$ of the fully protected tetrapeptide ester VIII ( 4.0 mmoles) in $50 \mathrm{ml}$ of methanol, catalysed by $400 \mathrm{mg}$ of palladium on charcoal $(10 \%)$, afforded the free tetrapeptide ester IX within 30 minutes, as was confirmed by thin layer chromatography: $R_{f}=0.13, \mathrm{Be}-\mathrm{An}(1: 1)$ (somewhat run-out spots); $=0.60$, chloro- 
form-methanol $(4: 1)$. The methanolic solution was then evaporated and the residue taken up in $10 \mathrm{ml}$ of dimethylformamide. $0.92 \mathrm{~g}$ (8 mmoles) of $N$-hydroxysuccinimide and 2.54 $\mathrm{g}$ of Z-Lys(Boc)-Pro-Val-Gly-OH (XIIa) $^{14}$ were added and the mixture was stirred until a homogeneous solution was obtained. It was cooled to $-20^{\circ}$ and finally $1.09 \mathrm{~g}$ of dicyclohexylcarbodiimide were added. The flask was kept in a deep-freezer $\left(\right.$ at $\left.-20^{\circ}\right)$ for some hours and then for some days in a refrigerator at $0^{\circ}$. Its contents were filtered $(0.72 \mathrm{~g}$ dicyclohexylurea) and the filtrate was concentrated in a high vacuum until a thick turbid oil remained. This residue could be transformed into a filterable powder by addition of ten volumes of ether. The weight of crude product (contaminated with dicyclohexylurea only) amounted to $6.21 \mathrm{~g}(103 \%) \mathrm{TS}: R_{f}=0.15, \mathrm{Be}-\mathrm{An}(1: 1) ;=0.80$ chloroform-methanol (4:1). $[\alpha]_{\mathrm{D}}{ }^{22}=-44.8 \pm 1.0^{\circ}$ ( $c=1$ in methanol). The octapeptide ester melted - in this state of purity -in the range of $145-155^{\circ}$ and was used as such in the next step (transformation into the amide XIVa).

$X I I I b, Y=O r n$. This intermediate was prepared in exactly the same way as described for the octapeptide ester containing lysine. Yield: quantitative; melting range: $140-145^{\circ}$. TS: $R_{f}=0.10, \mathrm{Be}-\mathrm{An}(1: 1) ;=0.88$, chloroform-methanol $(4: 1) .[\alpha]_{\mathrm{D}}{ }^{22}=-41.0 \pm 1.0^{\circ}$ $(c=1$ in methanol).

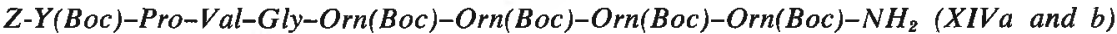

$X I V a, Y=L y s$. After some preliminary experiments the next procedure was adopted for the conversion of the octapeptide ester into its amide. The ester XIIIa $(1.5 \mathrm{~g})$ was suspended in a small amount of dry methanol and dissolved by addition of a saturated solution of dry ammonia in the same solvent to give a slightly cloudy solution. For optimal conversion this solution had to be left for three days at room temperature. The solution was then evaporated to dryness; a gelatinous precipitate was formed which was taken up in ether or diisopropyl ether. Filtration gave $1.350 \mathrm{~g} \mathrm{(91 \% )}$ of crude material. This amount and some pooled fractions obtained in the orienting experiments, together $2.0 \mathrm{~g}$, were purified by counter-current distribution in the system petroleum ether-ethyl acetatemethanol-water $(8: 16: 9: 6)$. After 153 transfers $r_{\max }$ proved to be 44 and consequently $K=0.41$. From the elements $38-56,1.74 \mathrm{~g}$ of pure octapeptide amide were obtained, melting at $202^{\circ}$. TS: $R_{f}=0.0$, Be-An $(1: 1) ;=0.85$, chloroform-methanol $(4: 1) .[\alpha]_{\mathrm{D}}{ }^{22}=$ $-33.2 \pm 1.0^{\circ}(c=1$ in methanol)

The amide crystallized with one molecule of water, which was not removed by drying over phosphorus pentoxide at $100^{\circ}$ and $10^{-3} \mathrm{~mm}$ pressure for 5 hours.

\section{Analysis: $\mathrm{C}_{71} \mathrm{H}_{120} \mathrm{~N}_{14} \mathrm{O}_{20}$ Calcd. C $56.56 \mathrm{H} 8.16 \mathrm{~N} 13.01$ \\ $\begin{array}{lllll}(1507.83) & \text { Found C } 56.3 & \text { H } 8.0 & \text { N } 13.0\end{array}$}

$X I V b, Y=O r n$. Aminolysis of the terminal methyl ester function in the pertinent octapeptide derivative XIIIb was carried out in the same way as described for the lysinecontaining derivative XIVa. The crude amide was purified by counter-current distribution using the same solvent system. In this case, after 150 transfers $r_{\max }$ was found to be 42 and thus $K=0.39$. From the elements $32-501.34 \mathrm{~g}$ of pure octapeptide amide were obtained. As this synthesis started with $1.5 \mathrm{~g}$ of methyl ester, the over-all yield after purification by counter-current distribution amounted to $90 \%$.

Melting point $198^{\circ} ;[\alpha]_{\mathrm{D}}{ }^{22}=-33.0 \pm 1.0^{\circ}\left(c=1\right.$, in methanol). TS: $R_{f}=0.0$. Be-An $(1: 1) ;=0.90$, chloroform-methanol $(4: 1)$. None of these criteria points to a significant distinction between the amides XIVa and XIVb.

This amide also firmly bound one molecule of water.

${ }^{14}$ R. Schwyzer, W. Rittel and A. Costopanagiotis, Helv. Chim. Acta 45. 2473 (1962). 
Analysis: $\quad \mathrm{C}_{70} \mathrm{H}_{118} \mathrm{~N}_{14} \mathrm{O}_{20} \cdot \mathrm{H}_{2} \mathrm{O}$ (1493.81)
Calcd. C 56.28 H $8.10 \mathrm{~N} 13.13$

Found C 56.1 H $8.0 \quad$ N 13.0

Scheme 2.

\section{$\mathrm{H}-\mathrm{Y}(\mathrm{Boc})-\mathrm{Pro}-\mathrm{Val}-\mathrm{Gly}-\mathrm{Orn}(\mathrm{Boc})-\mathrm{Orn}(\mathrm{Boc})-\mathrm{Orn}(\mathrm{Boc})-\mathrm{Orn}(\mathrm{Boc})-\mathrm{NH}_{2} . \mathrm{HCl},(\mathrm{XVa}$ and $b$ ).}

0.3 mmole of the protected amides XIVa and b (447 and $443 \mathrm{mg}$, respectively) were each dissolved in pure methanol to give a $1 \%$ solution. As neutral hydrogenolysis in the presence of $100 \mathrm{mg}$ palladium on charcoal (even after filtration of the catalyst and addition of a fresh amount of $100 \mathrm{mg}$ ) proved to be impracticably slow, hydrochloric acid $(0.3$ mmole) was added to give a starting concentration of $6 \times 10^{-3} \mathrm{M}$. At regular time intervals chromatographic controls were carried out. Although the starting material had not completely reacted after $25 \mathrm{~h}$, the reaction had to be interrupted because of the appearance of a new spot indicating the formation of a rather polar substance. Visual judgement of the result afforded a conversion of $90 \%$ and the presence of some $10 \%$ of this new slowly running contamination.

TS: $R_{f}=0.85$ (starting material, 10\%); $=0.76$ (amide hydrochloride, $80 \%$ ); $=0.17$ (newly formed impurity, 10\%), chloroform-methanol $(4: 1)$. Both octapeptide amides behaved quite analogously. A small difference in their formation consisted in the shorter reaction time $(3 \mathrm{~h})$ of $\mathrm{XIVb}$, with the concomitant formation of somewhat less of the slowly running side product. Both hydrogenolyses were carried out in duplicate. The crude amide hydrochlorides were used as such in the next step.

\section{Boc-X-Tyr-Ser-Met-Glu(OB $\left.u^{t}\right)-H i s-P h e-A r g-T r p-G l y-Y(B o c)-P r o-V a l-G l y-$ $\operatorname{Orn}(\mathrm{Boc})-\mathrm{Orn}(\mathrm{Boc})-\mathrm{Orn}(\mathrm{Boc})-\mathrm{Orn}(\mathrm{Boc})-\mathrm{NH}_{2} \cdot \mathrm{AcOH}(\mathrm{XVIIa-d})$}

The methanolic solutions, obtained by filtering off the catalyst from the suspensions after hydrogenolysis, were neutralized by addition of $0.3 \mathrm{mmole}(0.025 \mathrm{ml})$ of pyridine, in order to prevent further breakdown during evaporation of the apparently labile amides by residual hydrochloric acid. The solvent was then removed from each of the four solutions, leaving the crude amide hydrochlorides as a thin film in each of the vessels. To each of them

\section{Table II}

Experimental data of compounds a-d

\begin{tabular}{c|c|c|c|l|c|c}
\hline Code & $n$ & $r_{\max }$ & \multicolumn{1}{|c|}{$K$} & \multicolumn{1}{|c}{ Yield after ccd. } & $R_{f}$ & $\begin{array}{c}{[\alpha]_{\mathrm{D}}^{22}} \\
(c=0.5 \text { in AcOH })\end{array}$ \\
\hline XVIla & 200 & 37 & 0.23 & $492 \mathrm{mg}(58 \%)$ & $0.60^{\mathrm{b}}$ & $-49.0 \pm 1.0^{\circ}$ \\
XVIIb & 250 & 41 & 0.20 & $429(50 \%)$ & $0.60^{\mathrm{b}}$ & $-34.6 \pm 1.0^{\circ}$ \\
XVIIc & 280 & 50 & 0.22 & $284 \mathrm{and} 337 \mathrm{mg}^{\mathrm{a}}(73 \%)$ & $0.60^{\mathrm{c}}$ & $-32.2 \pm 1.0^{\circ}$ \\
XVIId & 275 & 45 & 0.20 & $458 \mathrm{mg}(54 \%)$ & $0.62^{\mathrm{c}}$ & $-25.3 \pm 1.0^{\circ}$ \\
\hline
\end{tabular}

$r_{\max }$ is the maximum in the counter-current distribution (ccd) curve after $n$ transfers; $K$ is distribution coefficient.

a Not completely homogeneous in thin layer chromatography

b TS, chloroform-methanol $(4: 1)$

c TS, chloroform-methanol $(3: 1)$ 
$10 \mathrm{ml}$ of dimethylformamide, $524 \mathrm{mg}$ of the pertinent protected decapeptide XVIa or b (0.36 mmole, $20 \%$ excess) and $41.4 \mathrm{mg}(0.36 \mathrm{mmole})$ of $N$-hydroxysuccinimide were added. The mixtures were stirred to effect dissolution of the decapeptide derivatives, which was not possible in both cases where the $N$-terminal seryl residue had the D-configuration. Finally, $75 \mathrm{mg}(0.36 \mathrm{mmole})$ of dicyclohexylcarbodiimide were added to each flask and the more or less turbid mixtures were stirred for three days.

The resulting suspensions were filtered, their clear filtrates concentrated by evaporation of the solvent under nitrogen in a high vacuum and then taken up in ethyl acetate and filtered. Each of the four crude octadecapeptide amides were purified by counter-current distribution in the system methanol-buffer-chloroform-carbon tetrachloride $(8: 3: 6: 2)$. One litre of buffer solution contained, besides doubly distilled water, $28.5 \mathrm{~g}$ of glacial acetic acid and $19.25 \mathrm{~g}$ of ammonium acetate.

Results are given in the Table II.

Amino acid analyses were carried out on a sample of each of the compounds of Table II, after hydrolysis with $6 \mathrm{~N}$-hydrochloric acid (diluted "Supra-pur" quality from Merck) for $24 \mathrm{~h}$ at $110^{\circ}$. Results were in accordance with the expected formulae.

\section{$\left[X^{1}, Y^{11}, O r n^{15-18}\right]-\beta$-Corticotropin-(1-18)-octadecapeptide amide (XVIII a-d)}

Trifluoroacetic acid (Fluka "purum-quality") was distilled and mixed with water $(10: 1)$. Samples of each compound $(100 \mathrm{mg})$ were dissolved in this mixture, taking $2 \mathrm{ml}$ for each sample. Dissolution took 1 to 2 minutes, giving slightly yellow solutions. After ten min. at room temperature, the acid was partially evaporated, the residue diluted with water and again concentrated. This process was repeated twice and the residue was freeze-dried.

Exchange of trifluoroacetate ions by acetate was performed in the usual way: a column of a weakly basic ion exchanger (Merck II, length $14 \mathrm{~cm}$; diameter $1.5 \mathrm{~cm}$ ) in the acetate cycle was loaded with an aqueous solution of the lyophilized product $(\sim 10 \mathrm{ml})$. After the solution had entered, the column was washed with doubly distilled water. The filtrate was collected as long as the Folin-Ciocalteux reaction was positive and the product was isolated by freeze-drying.

In each case nearly $80 \mathrm{mg}$ of white foam was obtained which represented the endproduct. Prior to weighing, the samples were dried over $\mathrm{P}_{2} \mathrm{O}_{5}$ at a pressure of $10^{-2} \mathrm{~mm}$, so the yields of this last step approach $100 \%$.

Chromatographic examination of the end-products revealed the absence of oxidized methionyl functions in the two analogues $\mathrm{D}$ and $\mathrm{E}$. The analogues $\mathrm{B}$ and $\mathrm{C}$, however, were contaminated with some material that contained sulphoxide (10 and $20 \%$, respectively). In the estimation of biological activity no allowance was made for the presence of these contaminants. The oxidation was probably caused by the occurrence of traces of peroxide in the acetic acid, that was incorporated in the buffer of the solvent system used for countercurrent distributions: On catalytic hydrogenation of a whole litre of A.R. glacial acetic acid $75 \mathrm{ml}$ of hydrogen ( 3 mmoles) were taken up.

Hydrogenation of acetic acid is an effective means of elimination of peroxides and is therefore strongly recommended.

\section{Acknowledgement}

We are grateful to Professor R.J.F. Nivard for stimulating and helpful discussions. The expert assistance of Mr. M. G.J.Buys in the amino acid analyses of the end products and of Mr. J. Diersmann in the performance of elemental analyses are also gratefully acknowledged. 
The investigations have been carried out under the auspices of the Netherlands Foundation for Chemical Research (SON) and with financial aid from the Netherlands Organization for the Advancement of Pure Research (ZWO).

(Received July 9th, 1970) 